\title{
MODIFIKASI KONSEP PARTICIPATORY RURAL APPRAISAL UNTUK PEMBEKALAN KULIAH KERJA NYATA MAHASISWA DI JAWA BARAT, INDONESIA
}

\author{
Zufialdi Zakaria $^{1}$, R. Irvan Sophian ${ }^{2}$ dan Nur Khoirullah ${ }^{3}$ \\ ${ }^{1}$ Dosen Fakultas Teknik Geologi, Universitas Padjadjaran \\ ${ }^{2}$ Mahasiswa Program Pasca Sarjana, Program Doktor, FTG, Unpad \\ ${ }^{3}$ Staf Laboratorium Geologi Teknik Fakultas Teknik Geologi. Universitas Padjadjaran \\ E-mail: zufialdi.zakaria@unpad.ac.id
}

\begin{abstract}
ABSTRAK. Modifikasi konsep PRA (Participatory Rural Appraisal) diperlukan bagi mahasiswa pada kegiatan KKN di Provinsi Jawa Barat, Indonesia. Konsep modifikasi PRA dapat digunakan sebagai alat komunikasi mahasiswa dengan penduduk lokal. Berbagai jenis gerakan tanah (longsor) terjadi di wilayah Jawa Barat sehingga menjadi salah satu wilayah yang paling rawan di dunia. Mahasiswa peserta KKN perlu dilengkapi dengan pengetahuan tentang kondisi wilayah Jawa Barat berdasarkan aspek geologi umum, juga mengenali informasi risiko dan bencana gerakan tanah, memahami penggunaan aplikasi Android yang berkaitan dengan bencana geologi, mahir menggunakan smartphone, mengetahui. beberapa metode penyampaian informasi dengan mudah dan komunikatif. Komunikasi yang baik dengan masyarakat lokal merupakan bagian dari tugas siswa sebagai salah satu agen pentaheliks dalam Model STARLET (Stabilisasi dan Rancangbangun Lereng Terpadu). Hasil Pre-Test 58 mahasiswa menunjukkan bahwa 98\% belum mengetahui konsep PRA, 91\% belum mengetahui konsep pentaheliks dalam model STARLET, 82\% tidak mengetahui bahwa Jawa Barat sangat rawan gerakan tanah, 88\% belum mengenal konsep Sistem Informasi Geografis Aplikasi Penanganan Bencana Gerakan Tanah (SIGAP Bencana Gerakan Tanah), 83\% belum mengenal model STARLET (Stabilisasi dan Rancangbangun Lereng Terpadu). Sebanyak 98\% mahasiswa dapat membedakan resiko dan bencana, $72 \%$ dapat membedakan kerentanan dan bahaya, dan $100 \%$ mereka memerlukan suatu metode penyuluhan agar masyarakat pedesaan mudah menerima informasi dan mengetahui penanganannya.
\end{abstract}

Kata kunci: Modifikasi PRA; bencana; longsor; Jawa Barat

\section{MODIFICATION OF RURAL APPRAISAL PARTICIPATORY CONCEPT FOR REAL EMPLOYMENT COLLABORATION IN WEST JAVA, INDONESIA}

\begin{abstract}
Modification of PRA concept (Participatory Rural Appraisal) is required for KKN activities (Kuliah Kerja Nyata or Student Study Service) in West Java. The modification of PRA concept can be used for students with local villager's communication. Various types of earth movement (landslide) occur in West Java region. West Java became the most vulnerable area of landslides in the world. Students participating KKN need to be equipped with knowledge about the condition of West Java region based on general geological aspects, also recognize the risk information and land movement disasters, understanding the use of Android applications related to geological disaster, proficient to using smartphones, knowing some method of delivering information easily and communicatively. Good communication with local communities is a part of student duty as one of pentahelix agents in the Model of STARLET (Stabilisasi dan Rancangbangun Lereng Terpadu). Pre-Test results of 58 students shows that 98\% didn't know the concept of PRA, 91\% didn't know the concept pentahelix in STARLET model, $82 \%$ didn't know that West Java is very vulnerable to earth movement (landslide), $88 \%$ not familiar with the concept of Geographic Information System - Application of Disaster Management or SIGAP Bencana Gerakan Tanah, $83 \%$ are not familiar with Model of STARLET. As many as $98 \%$ of students can distinguish the term of risks and disasters, $72 \%$ can distinguish the term of vulnerabilities and hazards, and $100 \%$ require a counseling method so that rural people can readily receive some information and know how to handle it.
\end{abstract}

Keywords: Modification of PRA; disaster; landslide; West Java

\section{PENDAHULUAN}

Kuliah Kerja Nyata merupakan bagian dari sistem pendidikan di perguruan tinggi di Indonesia. Universitas Padjadjaran, sebagai salah satu perguruan tinggi yang berada di wilayah Jawa Barat,

telah menetapkan wilayah Jawa Barat sebagai wilayah tujuan Kuliah Kerja Nyata bagi para mahasiswa. Selain itu, Universitas Padjadjaran mempunyai Pola Ilmiah Pokok (PIP) Bina Mulia Hukum dan Lingkungan Hidup dalam Pembangunan Nasional (Anonim, 2016). Dengan pola ilmiah pokok tersebut, maka aspek lingkungan hidup menjadi penting dalam Kuliah Kerja Nyata.
Kondisi fisik wilayah Jawa Barat perlu diketahui oleh para mahasiswa. Ditinjau dari aspek lingkungan hidup, Jawa Barat menyimpan kendala berupa kebencanaan geologi. Bencana geologi berupa tsunami, gempa bumi, letusan gunungapi, dan gerakan tanah berupa longsor, pernah terjadi di wilayah Jawa Barat. Dari empat jenis bencana geologi, gerakan tanah berupa longsor merupakan bencana geologi yang paling sering terjadi di Jawa Barat. Beberapa media massa memberitahukan bahwa Jawa Barat merupakan daerah yang paling rawan di dunia ditinjau dari aspek gerakan tanah berupa longsor (Beritasatu, 2013). Sepanjang tahun 2012, di Indonesia terdapat 116 kasus bencana gerakan tanah atau longsor yang mengakibatkan 128 
orang tewas. Jumlah kasus terbesar tercatat di Jawa Barat, yakni separuhnya atau sebanyak 58 kejadian dengan 33 korban meninggal. Daerah Jawa Barat yang rawan dan menelan banyak korban jiwa ialah Sukajaya dan Jasinga, Kabupaten Bogor, dan Taraju di Tasikmalaya, serta Soreang dan Kutawaringin di Kabupaten Bandung (Kompas, 2012). Menurut media massa lainnya, daerah yang memiliki risiko longsor sedang hingga tinggi dengan tingkat kerentanan longsor sedang sampai tinggi, yaitu di Kabupaten-kabupaten: Bogor, Sukabumi, Cianjur, Bandung, Bandung Barat, Garut, Sumedang, Tasikmalaya, Pangandaran, Ciamis, Subang, Kuningan, Majalengka dan Purwakarta (Tribunnews, 2017).

Pada umumnya, wilayah longsor tinggi berada pada zona fisiografi Pegunungan Selatan Jawa Barat yang terdiri atas batuan vulkanik dengan tanah residu yang tebal. Kondisi hujan juga mempengaruhi intensitas longsor, karena hujan dapat menjadi pemicu longsor. Tingginya curah hujan akan menurunkan faktor keamanan lereng sehingga menurunkan tingkat kestabilan lereng (Zakaria et al, 2015a). Prediksi longsor berdasarkan curah hujan bisa diperkirakan, Badan Nasional Peanggulangan Bencana misalnya, menerbitkan Peta Prediksi Longsor bulan Juli 2017 yang diterbitkan oleh BNPB (Anonim, 2017).

Pada wilayah-wilayah di Pegunungan Selatan Jawa Barat selain banyak topografi curam dengan lereng berkemiringan tinggi, terdapat faktor pemicu lainnya yaitu adanya pusat-pusat gempabumi baik di darat maupun di laut. Gempa dapat memicu longsoran, semakin besar kecepatan horizontal gempa, semakin kecil faktor keamanan lereng (Zakaria et al, 2015b) sehingga kestabilan lereng menjadi berkurang mulai dari stabil, kritis, kemudian labil.

Berdasarkan kondisi Jawa Barat seperti hal di atas, maka salah satu sasaran dari KKN tersebut adalah pemberdayaan masyarakat dalam menghadapi bencana gerakan tanah (longsor). Agar kegiatan berhasil dan tepat guna bagi masyarakat Jawa Barat, maka dibutuhkan pengetahuan, konsep dan metode untuk bekal para mahasiswa KKN yang sesuai dengan visi dan misi Universitas Padjadjaran.

Dalam kegiatan yang melibatkan masyarakat, terutama masyarakat pedesaan, konsep RRA (Rapid Rural Appraisal) dan PRA (Participatory Rural Appraisal) sering digunakan oleh para peneliti maupun lembaga swadaya masyarakat (LSM) untuk mendapatkan hasil yang bermanfaat bagi masyarakat pedesaan (Chambers, 1995). Agar masyarakat bisa berpartisipasi aktif, metode PRA mulai lebih diperhatikan. Untuk masalah KKN, mahasiswa sebagai bagian dari insan akademis dapat menjadi ujung tombak dalam penyampaian informasi yang powefull bagi masyarakat pedesaan, oleh sebab itu beberapa modifikasi terhadap konsep PRA sangat diperlukan.
Beberapa rumusan masalah dapat disampaikan sebagai berikut: Sejauhmanakah pengetahuan mahasiswa mengenai konsep atau metode penanganan bencana gerakan tanah (longsor)? Sejauhmanakah pengetahuan mahasiswa mengenai metode penyuluhan maupun penyampaian informasi untuk masyarakat di pedesaan agar dapat berhasil dan berguna? Bagaimanakah metode PRA (Participatory Rural Appraisal) dapat dimodifikasi untuk keperluan Kuliah Kerja Nyata para mahasiswa?

Berdasarkan rumusan masalah yang disampaikan di atas, maka beberapa tujuan dari makalah ini adalah untuk: 1) Mengetahui sejauhmana mahasiswa mengenal konsep dan metode untuk penanganan masalah gerakan tanah berupa longsor; 2) Mengetahui sejauhmana mahasiswa mengenal metode penyuluhan maupun penyampaian informasi yang berhasil dan tepat guna; 3 ) Membuat modifikasi dari metode PRA (Participatory Rural Appraisal) untuk keperluan Kuliah Kerja Nyata.

\section{METODE}

Beberapa metode untuk penanganan gerakan tanah berupa longsor dapat didekati dengan beberapa konsep yang sudah disampaikan di publik dalam bentuk seminar atau diskusi pakar, juga yang sudah terbit dalam bentuk artikel di jurnal atau buletin ilmiah, antara lain adalah konsep SIGAP Bencana Gerakan Tanah (atau Sistem Informasi Geografi Aplikasi Penanganan Bencana Gerakan Tanah), yaitu pendekatan dari sistem informasi geografis (Zakaria, 2011), dan model lain mengenai penanganan kestabilan lereng yang melibatkan empat komponen, yaitu model STARLET atau Stabilisasi dan Rancangbangun Lereng Terpadu (Zakaria, 2010). Pada awalnya, model ini membutuhkan keterpaduan empat komponen yaitu akademisi (ilmuwan), industri (pengusaha), pemerintah (pemerintah pusat maupun daerah), dan masyarakat sendiri (masyarakat desa, organisasi desa, atau lembaga swadaya masyarakat setempat). Model ini dimodifikasi lagi agar lebih tepat sasaran dengan menambah komponen kelima yaitu media massa ataupun informasi publik, sehingga dengan konsep pentaheliks, model ini diharapkan akan lebih berhasil dalam menangani masalah lereng rawan longsor (Zakaria, 2017). Kelima komponen perlu saling berhubungan dan saling berinteraksi dalam menangani bencana.

\section{Sigap dan Starlet}

Konsep SIGAP Bencana Gerakan Tanah membutuhkan beberapa informasi berupa data penting bagi penanganan gerakan tanah (longsor) secara sigap. Informasi akan dimasukkan dalam peta SIGAP Bencana Gerakan Tanah. Peta Sistem Informasi Geografis ini akan memuat data berupa informasi: 1) Geografis, 2) Geologi, 3) Geologi teknik (keteknikan batuan dan/atau tanah), 4) Iklim dan hidrogeologi, 5) Geomorfologi, 6) Seismotektonik, 7) Kependudukan, 8) Sosial dan 
ekonomi, 9) Lokasi fasilitas umum, 10) Manajemen bencana, 11) Gerakan tanah (orde longsor), 12) Sistem peringatan dini, 13) Penanganan darurat, 14) Kejadian longsor dan penanganannya, 15) Evaluasi dan rencana tindak lanjut, 16) Nomor, alamat, web-site, e-mail dan telepon penting.

Berbeda dengan konsep SIGAP Bencana Gerakan Tanah yang dimaksudkan sebagai media informasi, model STARLET dibangun untuk penanganan dan pencegahan. Model ini dimulai dari prosedur ilmiah untuk mendapatkan lereng rekayasa yang stabil dengan melibatkan komponen pentaheliks (Zakaria, 2017). Prosedurnya dimulai dengan: 1) Pemetaan Geologi Teknik dan pemetaan longsoran, 2) Analisis kestabilan lereng, (3) Simulasi rancang bangun lereng stabil, dan (4) Arahan manajemen lingkungan yang disertai monitoring lingkungan. Selain hal di atas, diperlukan pula partisipasi lima komponen, yaitu: 1) Para ilmuwan (akademisi), 2) Aparat pemerintah (pusat maupun daerah), 3) Masyarakat (masyarakat setempat atau lembaga swadaya masyarakat), 4) Industri (pengusaha), dan 5) media massa (Gambar 1 dan Gambar 2).

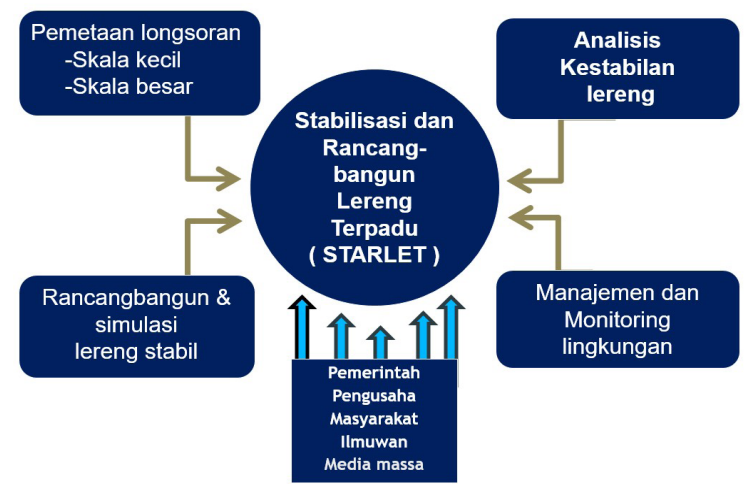

Gambar 1. Model STARLET dimodifikasi (Zakaria, 2017)

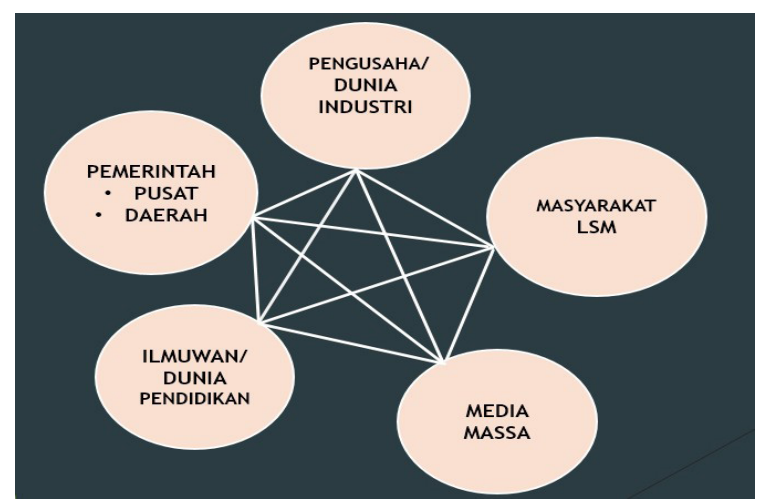

Gambar 2. Konsep pentaheliks dalam model STARLET (Zakaria, 2017)

Untuk menduung konsep di atas, dibutuhkan peta-peta tematik. Setiap desa seyogyanya mempunyai peta potensi desa yang dapat menggambarkan keadaan desa secara rinci. Peta yang baik adalah peta sesuai dengan thema yang diinginkan, juga peta yang dapat menggambarkan keadaan suatu wilayah dengan jelas meliputi bagian-bagian penting, seperti: judul peta, skala peta, arah peta, kordinat atau grid, legenda, tanggal pembuatan, penyusun peta, penerbit peta dan inset peta (Bafdal, dkk., 2014). Pengetahuan peta dan potensi maupun kendala desa dapat menjadi pengetahuan baru bagi masyarakat pedesaan. Saat KKN, mahasiswa dapat mendorong masyarakat desa untuk lebih memahami fasilitas, potensi dan kendala yang ada di Desa masingmasing. Khusus mengenai Peta Potensi Desa, peta ini dapat tersusun atas bantuan Aparat Desa, Perwakilan Dusun dan Mahasiswa KKN (Amaru, dkk., 2013).

\section{RRA dan PRA}

Metode Participatory Rural Appraisal (PRA) merupakan perkembangan dari metode-metode terdahulu, diantaranya teknik Rapid Rural Appraisal (RRA) yang dianggap kurang dalam mengajak stakeholder untuk berpartisipasi dalam program atau kebijakan (Chambers, 1995). Kelebihan dan kekurangan dua metode ini banyak dipelajari untuk mendapatkan hasil yang tepat sasaran. Hubungan antara beberapa komponen, yaitu peneliti, pemerintah, dan masyarakat pedesaan dalam dua metode tersebut mempunyai beberapa perbedaan.

Filosofi, pendekatan dan Rapid Rural Appraisal (RRA)muncul pada akhir 1970an. Pada awalnya ditujukan untuk masalah mengenai pariwisata pembangunan pedesaan dan pengetahuan teknis pribumi. Metode RRA sendiri secara paralel di berbagai belahan dunia berupaya mencari cara yang lebih baik bagi orang luar untuk belajar tentang kehidupan dan kondisi pedesaan.

Setelah muncul konsep RRA, kemudian muncul metode Participatory Rural Appraisal (PRA). Metoda ini mengutamakan partisipasi aktif dari masyarakat desa sendiri. Namun timbul pertanyaan apakah PRA dapat terpisah dari RRA. Para ahli memandang bahwa nama metode menjadi tidak penting, karena banyak sejumlah besar nama metode untuk pendekatan dan pembelajaran tentang kehidupan dan kondisi pedesaan (Chambers, 1995). Ringkasan perbandingan dari RRA dan PRA diberikan dalam Tabel 1 di bawah ini:

Tabel 1. Perbandingan RRA dan PRA ditinjau dari beberapa aspek (Chambers, 1995)

\begin{tabular}{|c|c|c|c|}
\hline No & Keterangan & RRA & PRA \\
\hline 1 & Periode & $\begin{array}{l}\text { Akhir 1970-an, } \\
\text { 1980-an }\end{array}$ & $\begin{array}{l}\text { Akhir 1980-an, } \\
1990\end{array}$ \\
\hline 2 & $\begin{array}{l}\text { Inovator } \\
\text { utama }\end{array}$ & $\begin{array}{l}\text { Berbasis di } \\
\text { universitas }\end{array}$ & LSM \\
\hline 3 & $\begin{array}{l}\text { Pengguna } \\
\text { utama }\end{array}$ & $\begin{array}{l}\text { Lembaga } \\
\text { bantuan, } \\
\text { Universitas }\end{array}$ & $\begin{array}{l}\text { LSM, Pemerintah } \\
\text { Organisasi } \\
\text { lapangan }\end{array}$ \\
\hline 4 & $\begin{array}{l}\text { Sumber daya } \\
\text { utama tadi } \\
\text { terlewatkan }\end{array}$ & $\begin{array}{l}\text { Pengetahuan } \\
\text { masyarakat } \\
\text { setempat }\end{array}$ & $\begin{array}{l}\text { Kemampuan } \\
\text { masyarakat } \\
\text { setempat }\end{array}$ \\
\hline 5 & Inovasi utama & Metode & Tingkah laku \\
\hline 6 & $\begin{array}{l}\text { Mode } \\
\text { dominan }\end{array}$ & $\begin{array}{l}\text { Elisitif, } \\
\text { ekstraktif }\end{array}$ & $\begin{array}{l}\text { Memfasilitasi } \\
\text { partisipatif }\end{array}$ \\
\hline 7 & Tujuan ideal & Belajar dari luar & $\begin{array}{l}\text { Pemberdayaan } \\
\text { masyarakat } \\
\text { setempat }\end{array}$ \\
\hline
\end{tabular}


Beberapa metode, seperti pengamatan langsung, dan wawancara semi terstruktur, telah ditekankan di RRA namun dapat menjadi bagian penting dari PRA. Metode lain dapat disampaikan, seperti pemetaan partisipatif, dimana masyarakat lokal bisa diajak membuat peta mereka sendiri, dan kegiatan partisipatif lainnya. Beberapa metode yang ditekankan dalam RRA juga dapat digunakan dalam model PRA (Chambers, 1995).

\section{Modifikasi Metode Participatory Rural Appraisal (PRA)}

Metode PRA dianggap sudah lebih baik dari metode sebelumnya. Metode ini berupaya memberdayakan masyarakat pedesaan dengan bantuan dari orang luar sebagai fasilitator. Modifikasi PRA diperlukan, terutama pada masalah informasi yang dimiliki, dianalisis, dan digunakan oleh masyarakat pedesaan. Informasi, analisis dan penggunaan informasi, perlu digabungkan dengan informasi dari mahasiswa KKN sebagai orang luar sehingga dapat bersama-sama menangani permasalahan yang ada. Mahasiswa dapat membawa informasi dari luar melalui smartphone yang sekarang sudah beredar sampai pelosok-pelosok pedesaan. Peran mahasiswa sebagai orang luar adalah mitra, bukan hanya sebagai fasilitator, karena informasi dari masyarakat pedesaan dapat digabung dengan informasi dari mahasiswa yang didapat dari kajian ilmiah, atau dari pemerintah melalui lembaga resmi seperti Pusat Vulkanologi dan Mitigasi Bencana Geologi (PVMBG) - Badan Geologi, dan Badan Nasional Penanggulangan Bencana (Tabel 2).

Mahasiswa dapat mengajarkan aplikasi Andorid untuk masalah resiko dan bencana yang sudah diterbitkan secara luas melalui GooglePlay yang dapat diinstal pada Hand Phone pribadi dengan sistem Android. Aplikasi yang sudah biasa digunakan adalah Magma Indonesia (Magma, 2015) dan InaRISK (InaRISK, 2017) untuk Indonesia, dan RSOE EDIS (2013) untuk wilayah dunia, termasuk Indonesia. Tiga aplikasi ini memberikan informasi kejadian berbagai bencana.

Magma Indonesia (2015) menampilkan semua informasi semua jenis bencana geologi yang terjadi setiap hari di Indonesia, InaRISK (2017) menampilkan wilayah resiko bencana di Indonesia, sedangkan RSOE EDIS (2013) memberikan informasi semua jenis bencana (bencana geologi dan non geologi) yang terjadi di dunia.

Beberapa situs dapat bermanfaat untuk mendapatkan informasi kebencanaan yang terjadi saat ini. Misalnya situs BMKG (http://www.bmkg. go.id/) dan BNPB (https://www.bnpb.go.id/) yang menampilkan kondisi di wilayah Indonesia, serta RSOE (http://hisz.rsoe.hu/alertmap/index2.php) yag menampilkan kejadian semua jenis dan lokasi bencana di dunia. Situs-situs tersebut merupakan situs internet yang menyampaikan data penting mengenai berbagai kebencanaan setiap hari, termasuk kebencanaan geologi berupa gerakan tanah (longsor) setiap saat.

\section{Teknik Pengumpulan Data Mahasiswa Calon Peserta KKN}

Dalam kajian ini, teknik pengumpulan data dilakukan pada saat acara Seminar Geologi Teknik dengan tema Geologi Teknik untuk Menunjang Kesejahteraan Masyarakat Pedesaan (1) - Aspek Kebencanaan Gerakan Tanah. Dalam seminar dibahas mengenai:

1. Gerakan Tanah (longsor) di Jawa Barat

2. Peran Ilmu Geologi Teknik dalam Pembangunan dan Pengembangan Wilayah

3. Analisis Kestabilan Lereng, Aspek Penting dalam Mitigasi Gerakan Tanah

4. Metoda Modifikasi Penilaian Partisipatif Pedesaan (Modified Participatory Rural Appraisal)

Sumber data adalah para peserta seminar yang terdiri atas mahasiswa yang belum pernah melakukan KKN. Cara analisis data adalah dengan membandingkan pengetahuan di awal kegiatan melalui Pre-Test, dan diakhiri dengan Post-Test. Perbandingan antara kedua uji tersebut akan dianalisis dan dibuat kesimpulan.

Saat seminar, mahasiswa dikenalkan kepada beberapa aplikasi Android yang berhubungan dengan gerakan tanah, yang sudah bisa diunduh dengan gratis. Aplikasi pertama adalah Magma Indonesia (2015), dikembangkan oleh Pusat Vulkanolog dan Mitigasi Bencana Geolog - Badan Geologi. Aplikasi kedua adalah

Tabel 2. Rangkaian unit RRA, PRA dan Modifikasi PRA

\begin{tabular}{|c|c|c|c|}
\hline Sifat proses & RRA & PRA & Modifikasi PRA \\
\hline Mode & Ekstraktif-elastis & Berbagi-pemberdayaan & Berbagi-pemberdayaan \\
\hline Peran orang luar & Peneliti & Fasilitator & Mitra, Fasilitator, Peneliti \\
\hline $\begin{array}{l}\text { Informasi yang } \\
\text { dimiliki, dianalisis } \\
\& \text { digunakan oleh: }\end{array}$ & Orang luar & Orang lokal & Mahasiswa KKN dan Masyarakat pedesaan \\
\hline $\begin{array}{l}\text { Metode yang } \\
\text { digunakan }\end{array}$ & $\begin{array}{l}\text { Penyuluhan dari pemerintah ke } \\
\text { masyarakat lokal. Penanganan } \\
\text { masalah di desa dilaksanakan } \\
\text { atas usul pemerintah. }\end{array}$ & $\begin{array}{l}\text { Masyarakat lokal menyampaikan } \\
\text { informasi yang diketahuinya } \\
\text { untuk diarahkan oleh fasilitator } \\
\text { dalam menangani masalah di } \\
\text { desanya. }\end{array}$ & $\begin{array}{l}\text { Masyarakat desa menyampaikan informasi } \\
\text { yang diketahuinya, ditambah dengan } \\
\text { informasi dari orang luar sehingga dapat } \\
\text { berbagi informasi dan bersama-sama } \\
\text { mencari tahu penanganan masalah. }\end{array}$ \\
\hline
\end{tabular}


InaRISK (2015) dikembangkan oleh Badan Nasional Penanggulangan Bencana. Selain itu, web-site penting yang digunakan sebagai sumber informasi yang selalu up-date, ditampilan dalam bentuk demo.

\section{HASIL DAN PEMBAHASAN}

\section{Analisis Pre-Test dan Post-Test}

Pertanyaan yang disampaikan adalah sekitar pengetahuan mengenai hal-hal yang bermanfaat untuk kegiatan mahasiswa dalam Kuliah Kerja Nyata (KKN), penetahuan kondisi geologi Jawa Barat, pengetahuan mengenai bencana longsor (gerakan tanah), dan metode maupun konsep dalam kajian geologi teknik maupun penyuluhan kepada masyarakat. Pertanyaan dan hasil disampaikan sebagai berikut:

1. Pernahkan Anda melaksanakan kegiatan kemahasiswaan di Jawa Barat selain Kuliah Kerja Nyata? Pada saat Pre-Test, 53\% menjawab Ya, sedangkan 47\% menjawab Tidak. Pada saat Post-Test, 59\% menjawab Ya, dan masih terdapat 41\% menjawab Tidak. Sebagian mahasiswa pernah melaksanakan kegiatan kemahasiswaan selain KKN di Jawa Barat sebanyak 59\%, sebagian lagi (sebanyak 41\%) belum pernah. Mereka yang pernah melaksanakan kegiatan kemahasiswaan sebelum KKN, diharapkan dapat berhasil dalam melaksanakan KKN kelak. Pada saat Post-Test, sebagian mahasiswa menyadari bahwa ternyata mereka pernah mengikuti kegiatan kemahasiswaan di wilayah Jawa Barat, sehingga terjadi peningkatan dari 53\% saat Pre-Test menjadi 59\% saat Post-Test.

2. Apakah Jawa Barat merupakan wilayah paling rawan longsor di dunia ini? Pada saat Pre-Test, 17\% menjawab Ya, dan 83\% menjawab Tidak. Pada saat Post-Test, 94\% menjawab Ya, dan 6\% menjawab Tidak. Sebanyak 17\% mahasiswa mengetahui bahwa Jawa Barat merupakan wilayah yang paling banyak longsor di dunia. Informasi dari media massa telah menyampaikan kondisi tersebut, namun sebagian mahasiswa sebanyak $83 \%$ belum pernah mengetahui informasi tersebut. Pada saat Post-Test, informasi bahwa wilayah Jawa Barat merupakan daerah yang paling rawan sedunia telah tersampaikan dengan data-data yang dihadirkan saat presentasi, sehingga sebanyak 94\% mahasiswa menyadari, sementara 6\% masih belum yakin bahwa Jawa Barat sangat rawan longsor.

3. Apakah Anda mengetahui dan dapat membedakan antara Resiko dan Bencana? Pada saat Pre-Test, sebanyak 98\% mahasiswa sudah mengetahui istilah resiko dan bencana, sebanyak $2 \%$ tidak tahu. Setelah Post-Test, 100\% mahasiswa mengetahui istilah tersebut.

4. Apakah Anda mengetahui dan dapat membedakan antara Kerentanan dan Bahaya? Pada saat Pre-
Test, sebanyak $72 \%$ mahasiswa sudah mengetahui istilah antara kerentanan dan bahaya, sebanyak 28\% tidak mengetahui. Setelah Post-Test, 100\% mahasiswa mengetahui kedua istilah tersebut.

5. Apakah pernah mendengar konsep sistem informasi geografis yang disebut SIGAP Bencana Longsor (Sistem Informasi Geografis Aplikasi Penanganan Bencana Longsor)? Pada saat Pre-Test, 12\% mahasiswa sudah mengetahui SIGAP Bencana Gerakan Tanah melalui artikel ilmiah yang sudah terbit, sementara $88 \%$ belum mengetahui atau belum pernah membaca artikel tersebut. Setelah dilaksanakan presentasi dan dilakukan Post-Test, maka $100 \%$ telah mengetahui bahwa ada konsep system informasi geografis tersebut.

6. Apakah Anda mengetahui konsep penanganan lereng rawan longsor melalui Model STARLET Stabilisasi dan Rancangbangun Lereng Terpadu? Pada saat Pre-Test, 17\% menjawab Ya. 83\% menjawab Tidak Tahu/ Pada saat Post-Test, 88\% menjawab Ya. 12\% menjawab Tidak Tahu. Model STARLET - Stabilisasi dan Rancangbangun Lereng Terpadu pernah disterbitkan pada majalah ilmiah IJOG (Indonesian Journal on Geoscience) pada tahun 2010. Pada saat presentasi disampaikan pula konsep ini, namun tenyata ada $12 \%$ yang masih juga belum memahami konsep ini.

7. Apakah Anda mengetahui konsep pentahelix dalam Model Stabilisasi dan Rancangbangun Lereng Terpadu? Pada saat Pre-Test, 9\% menjawab Ya. 91\% menjawab Tidak Tahu. Pada saat Post-Test, 86\% menjawab Ya. 14\% menjawab Tidak Tahu. Pada saat presentasi selesai, $86 \%$ sudah mengetahui, namun masih terdapat $14 \%$ mahasiswa yang masih belum memahami bahwa mahasiswa adalah agen dalam akademisi di dalam konsep pentahelix.

8. Apakah Anda mengetahui konsep penyampaian informasi dalam penyuluhan melalui PRA (Participatory Rural Appraisal)?Pada saat Pre-Test, 2\% menjawab Ya. 98\% menjawab Tidak Tahu. Pada saat Post-Test, 80\% menjawab Ya. 20\% menjawab Tidak Tahu. Kenyataannya bahwa hanya 2\% yang mengetahui konsep PRA, dan 98\% masih belum tahu konsep tersebut. Setelah presentasi, terjadi peningkatan jumlah peserta yang mengetahui konsep PRA menjadi sebanyak 80\%, namun $20 \%$ lagi masih belum mengetahui konsep PRA ini.

9. Apakah Anda yakin bahwa geologi teknik dapat mendukung kesejahteraan rakyat melalui informasi potensi dan kendala wilayah? Pada saat Pre-Test, 98\% menjawab Ya. 2\% menjawab Tidak Tahu. Hasil PostTest menunjukkan 100\% mereka mengetahui bahwa geologi teknik dapat mendukung kesejahteraan rakyat melalui informasi potensi dan kendala wilayah.

10. Perlukah suatu metode penyuluhan agar masyarakat pedesaan mudah menerima informasi dan menge- 
tahui penanganannya? Secara keseluruhan, saat Pre-Test maupun Post-Test 100\% mahasiswa peserta test telah menyadari perlunya metode penyuluhan agar masyarakat dapat mudah menerima informasi dan mengetahui penanganannya.

Berdasarkan penilaian Pre-Test terhadap 58 mahasiswa peserta seminar (Tabel 3), maka didapatkan hasil sebagai berikut: Dari seluruh peserta, hasil test menunjukkan bahwa 98\% belum mengetahui konsep PRA, 91\% belum mengetahui konsep pentaheliks (dalam model STARLET), $82 \%$ tidak mengetahui bahwa Jawa Barat sangat rawan gerakan tanah, $88 \%$ belum mengenal SIGAP Bencana Gerakan Tanah, 83\% belum mengenal model STARLET. Sebanyak $98 \%$ mahasiswa dapat membedakan resiko dan bencana, $72 \%$ dapat membedakan kerentanan dan bahaya, dan 100\% mereka memerlukan suatu metode penyuluhan agar masyarakat pedesaan mudah menerima informasi dan mengetahui penanganannya.

Setelah Post-Test, terjadi peningkatan 100\% mereka dapat membedakan istilah resiko dan bencana, $100 \%$ istilah dapat membedakan istilah kerentanan dan bahaya, 100\% mengetahui adanya konsep SIGAP Bencana Longsor (Sistem Informasi Geografis Aplikasi Penanganan Bencana Longsor), 100\% yakin bahwa geologi teknik dapat mendukung kesejahteraan rakyat melalui informasi potensi dan kendala wilayah, dan $100 \%$ memerlukan suatu metode penyuluhan agar masyarakat pedesaan mudah menerima informasi dan mengetahui penanganannya.
Berdasarkan penilaian secara keseluruhan, mahasiswa membutuhkan pembekalan sebelum melaksanakan KKN ke lapangan. Pembekalan berupa informasi mengenai kondisi daerah setempat, juga beberapa teori, konsep dan metode untuk diberikan kepada mahasiswa yang akan mengikuti KKN. Pengenalan Jawa Barat sebagai wilayah rawan bencana gerakan tanah (longsor), perlu disampaikan kepada mahasiswa, karena beberapa kabupaten sering dilanda gerakan tanah (longsor). Diharapkan mereka dapat mengetahui dan bisa melaksanakan kegiatan KKN terutama di wilayah rawan longsor. Mahasiswa sebagai agen dalam dunia akademisi, adalah merupakan bagian dalam konsep PRA yang dimodifikasi.

Pembekalan bagi mahasiswa peserta KKN bisa diganti dengan pelatihan atau seminar bagi para mahasiswa geologi maupun non-geologi secara bersamasama. Pengetahuan sosial dibutuhkan bagi mahasiswa teknik geologi. Sebaliknya, pengetahuan teknik geologi dibutuhkan pula oleh mahasiswa sosial dan mahasiswa non geologi lain pada umumnya.

\section{SIMPULAN}

Mahasiswa sebagai agen di dalam bagian komponen pentaheliks, yaitu akademisi atau ilmuwan, memiliki peran penting untuk keberhasilan beberapa metode dalam penanganan bencana geologi, khususnya gerakan tanah (longsor). KKN para mahasiwa yang dilaksanakan di wilayah Jawa Barat, perlu dibekali informasi penting yang berguna untuk diri sendiri dan untuk masayarakat

Tabel 3. Hasil Pre-Test dan Post-Test

\begin{tabular}{|c|c|c|c|c|c|}
\hline \multirow{3}{*}{ No. } & \multirow{3}{*}{ Pertanyaan } & \multicolumn{2}{|c|}{ YA / PERNAH } & \multicolumn{2}{|c|}{ TIDAK TAHU } \\
\hline & & PRE-TEST & POST-TEST & PRE-TEST & POST-TEST \\
\hline & & \multicolumn{2}{|c|}{$\%$} & \multicolumn{2}{|c|}{$\%$} \\
\hline 1 & $\begin{array}{l}\text { Pernahkan Anda melaksanakan kegiatan kemahasiswaan di } \\
\text { Jawa Barat selain Kuliah Kerja Nyata. }\end{array}$ & 53 & 59 & 47 & 41 \\
\hline 2 & $\begin{array}{l}\text { Apakah Jawa Barat merupakan wilayah paling rawan longsor } \\
\text { di dunia ini? }\end{array}$ & 17 & 94 & 83 & 6 \\
\hline 3 & $\begin{array}{l}\text { Apakah Anda mengetahui dan dapat membedakan antara } \\
\text { Resiko dan Bencana? }\end{array}$ & 98 & 100 & 2 & 0 \\
\hline 4 & $\begin{array}{l}\text { Apakah Anda mengetahui dan dapat membedakan antara } \\
\text { Kerentanan dan Bahaya? }\end{array}$ & 72 & 100 & 28 & 0 \\
\hline 5 & $\begin{array}{l}\text { Apakah pernah mendengar konsep system informasi geografis } \\
\text { SIGAP Bencana Longsor (Sistem Informasi Geografis Aplikasi } \\
\text { Penanganan Bencana Longsor)? }\end{array}$ & 12 & 100 & 88 & 0 \\
\hline 6 & $\begin{array}{l}\text { Apakah Anda mengetahui konsep penangan lereng } \\
\text { rawan longsor melalui Model STARLET - Stabilisasi dan } \\
\text { Rancangbangun Lereng Terpadu? }\end{array}$ & 17 & 88 & 83 & 12 \\
\hline 7 & $\begin{array}{l}\text { Apakah Anda mengetahui konsep pentahelix dalam Model } \\
\text { Stabilisasi dan Rancangbangun Lereng Terpadu? }\end{array}$ & 9 & 86 & 91 & 14 \\
\hline 8 & $\begin{array}{l}\text { Apakah Anda mengetahui konsep penyampaian informasi } \\
\text { dalam penyuluhan melalui PRA (Participatory Rural } \\
\text { Appraisal)? }\end{array}$ & 2 & 80 & 98 & 20 \\
\hline 9 & $\begin{array}{l}\text { Apakah Anda yakin bahwa geologi teknik dapat mendukung } \\
\text { kesejahteraan rakyat melalui informasi potensi dan kendala } \\
\text { wilayah? }\end{array}$ & 98 & 100 & 2 & 0 \\
\hline 10 & $\begin{array}{l}\text { Perlukah suatu metode penyuluhan agar masyarakat pedesaan } \\
\text { mudah menerima informasi dan mengetahui penanganannya? }\end{array}$ & 100 & 100 & 0 & 0 \\
\hline
\end{tabular}


yang akan ditemuinya dalam suatu kesempatan interaksi. Berdasarkan test sederhana pada saat seminar geologi teknik, maka disimpulkan bahwa: 1) Sebagian mahasiswa belum menyadari bahwa beberapa metode dan konsep bencana gerakan tanah (longsor) perlu diketahui jika yang bersangkutan akan mengikuti KKN di wilayah rawan gerakan tanah (longsor). Konsep pentaheliks yang dimanfaatkan pada model Stabilisasi dan Rancangbangun Lereng Tepadu, diperlukan supaya penanganan masalah gerakan tanah berupa longsor yang dapat ditangani secara bersama-sama; 2) Mahasiswa belum mengenal metode penyuluhan maupun penyampaian informasi agar berhasil dan tepat guna, namun demikian, mahasiswa menyadari perlunya suatu metode yang bisa dilaksanakan dalam KKN yang dapat melibatkan masyarakat lokal, sehingga dapat memberdayakan masyarakat dalam upaya meningkatkan kapasitas untuk menghadapi bencana di daerahnya; 3) Modifikasi dari metode PRA (Participatory Rural Appraisal) untuk keperluan Kuliah Kerja Nyata sangat dibutuhkan. Mahasiwa sebagai orang luar dapat bertindak sebagai fasilitator maupun sebagai mitra dengan masyarakat desa. Untuk itu, maka informasi yang dimiliki masing-masing dapat saling berbagi.

\section{UCAPAN TERIMAKASIH}

Ucapan terima kasih disampaikan kepada Direktur Riset, Pengabdian kepada Masyarakat dan Inovasi yang telah memberikan kesempatan untuk melaksanakan penelitian dan pengabdian masyarakat di wilayah Kampus Jatinangor dengan Nomor Kontrak: 1364/UN6.3.1/ PM/2017 Tanggal 30 Mei 2017 melalui dana Hibah Pengabdian kepada Masyarakat skema Mono Tahun. Ucapan terima kasih juga disampaikan kepada Dekan Fakultas Teknik Geologi, Universitas Padjadjaran yang telah memberikan fasilitas tempat pelaksanaan seminar, juga kepada para asisten dan dosen dari kelompok Laboratorium Geologi Teknik FTG Unpad sebagai panitia penyelenggara Seminar Geologi Teknik.

\section{DAFTAR PUSTAKA}

Amaru, K., Asdak, C. dan., Balia, R. 2013. Penyuluhan Pengenalan Peta dan Identifikasi Potensi Daerah untuk Pembuatan Peta Potensi Desa di Desa Jatimekar dan Desa Cijati Kecamatan Situraja Kabupaten Sumedang. Dharmakarya: Jurnal Aplikasi Ipteks untuk Masyarakat Vol. 2, No. 1, Mei 2013: 32- 40

Anonim. 2016. Rencana Induk Riset Universitas Padjadjaran (RIR Unpad) 2016-2020, Universitas Padjadjaran, 148 hal.

Anonim. 2017. Peta Prediksi Longsor 27 Juli 2017 Badan Nasional Penanggulangan Bencana (BNPB) http://geospasial.bnpb.go.id/wp-content/ uploads/2017/07/PETA - PREDIKS ILONGSOR-2707-2017-Pkl-13_350DPI.jpg, diakses tanggal 16 November 2017, pukul 20.05

Bafdal, N., Balia, R.L., Dwiratna, S. dan Amaru, K. 2014. Penyusunan Peta Potensi Desa Agrowisata Berbasis Masyarakat di Desa Cibuntu Kecamatan Pasawahan Kabupaten Kuningan. Dharmakarya: Jurnal Aplikasi Ipteks untuk Masyarakat Vol. 3, No. 2, Nopember 2014: 81-87

Beritasatu. 2013. Jabar Daerah Paling Rawan Longsor di Dunia, diakses pada tanggal 17 November 2017, pukul 11:30, alamat situs: http:/www. beritasatu.com/nasional/104291-jabar-daerahpaling-rawan-longsor-di-dunia.html

Chambers, R. 1995. Rural Appraisal: Rapid, Relaxed and Participatory, from Book: Participatory Rural Appraisal methods and applications in rural planning. (ed.: Mukherjee, A), Vikas Publishing House PVT Ltd., 1-62

InaRISK. 2017. Bagaimana Risiko Wilayah Kita? Diakses pada tanggal 16 November 2017, pukul 13:40, alamat situs: http://inarisk.bnpb.go.id/

Kompas. 2012. Longsor Terbanyak di Jawa Barat, diakses pada tanggal 17 November 2017, pukul 12:30, alamat situs: http://regional. kompas.com/read/2012/12/29/03460723/ Longsor.Terba-nyak.di.Jawa.Barat

Magma Indonesia. 2015. Magma Indonesia (C) 20152017 PVMBG. All rights reserved. [v0.1.3 Alpha] Privacy Policy, Diakses 16 November 2017, pukul 13:52, https://magma.vsi.esdm.go.id/

RSOE EDIS. 2013. RSOE EDIS Notifier Lite. (C) 2013, The National Association of Radio Distress-Signalling and Info Communications (RSOE) \& Emergency and Disaster Information Service (EDIS). Diakses pada tanggal 16 November 2017, pukul 18:33, alamat situs: https://play.google.com/store/ apps/details? $\mathrm{id}=$ org.rsoe.android.edis_pms

Tribunnews. 2017. BNPB Ungkap 3 Propinsi Bencana Longsor Terbanyak, diakses pada tanggal 17 November 2017, pukul 11:42. alamat situs: http:// www.tribunnews.com/nasional/2017/10/31/bnpb-ungkap-3-provinsi-bencana-longsorterbanyak

Zakaria, Z. 2010. Model STARLET, Suatu Usulan Untuk Mitigasi Bencana Longsor dengan Pendekatan Genetika Wilayah. Jurnal Geologi Indonesia. Vol. 5, No. 2. Juni 2010. hal. 93-112

2011. SIGAP Gerakan Tanah, Sistem Informasi Geografis Aplikasi Penanganan Gerakan 
Tanah, Bulletin of Scientific Contribution, Volume 9, Nomor 1, April 2011: 49-60

, Jihadi, L.H., Sabila, Z.S., \& Oscar, A.W. 2015a. Simulation of Slope Stability in the Dry and Rainy Season at Jatinangor, District of Sumedang, West Java. Proceedings of The 2nd International Conference HanoiGEO, "Engineering Geology in Respond to Climate Change and Sustainable Development of Infrastructure”. pp. 365-367

Hirnawan, F. Widayati, S. 2015b. Rain and Earthquake-induced Landslides in West Java, Indonesia, Case Study in Subang Area near the
Baribis Fault, with Implications for an Early Warning System, Engineering Geology for Society and Teritory, Volume 2, 2015, pp 637640

, 2017, Mitigasi Bencana Gerakan Tanah dan Longsor Melalui Penataan Ruang, Diskusi Pakar tentang Penataan Ruang Kawasan Rawan Bencana (KRB) di Kabupaten Pacitan, Jakarta 18 April 2017, Direktorat Penataan Kawasan, Direktorat Jenderal Tata Ruang, Kementerian Agraria dan Tata Ruang Badan Pertanahan Nasional 